\title{
Robotic thyroidectomy using a transaxillary approach can be performed by experienced surgeons in selected surgical clinics
}

\author{
Murat Enoz • Hasan Mete Inancli • Gunter Hafiz
}

Published online: 9 July 2010

(C) Springer Science+Business Media, LLC 2010

We read the article by Kang et al. [1] entitled RobotAssisted Endoscopic Surgery for Thyroid Cancer: Experience With the First 100 Patients with a great interest. These authors emphasized that robot-assisted endoscopic thyroid operations using a gasless transaxillary approach is a feasible, safe, and effective method for selected patients with thyroid cancer [1].

However, this robotic approach has several disadvantages. The surgeon must be experienced before performing the robotic operation. This new technique needs a da Vinci Surgical System, and its set of instruments requires excessive time. Moreover, the procedure may not be suitable for removing large thyroid tumors. Management complications due to this new technique may be require additional neck incisions and thus a longer operation time due to the narrow surgical area with transaxillary approach.
Consequently, robotic thyroidectomy with a transaxillary approach is not a simple method. It can be performed by experienced surgeons in selected surgical clinics.

Disclosures Murat Enoz, Hasan Mete Inancli, and Gunter Hafiz have no conflicts of interest or financial ties to disclose.

\section{Reference}

1. Kang SW, Jeong JJ, Yun JS, Sung TY, Lee SC, Lee YS, Nam KH, Chang HS, Chung WY, Park CS (2009) Robot-assisted endoscopic surgery for thyroid cancer: experience with the first 100 patients. Surg Endosc 11:2399-2406

M. Enoz

Department of Otorhinolaryngology and Head and Neck

Surgery, Special Yenibosna Safa Hospital, Istanbul, Turkey

H. M. Inancli

Department of Otorhinolaryngology and Head and Neck

Surgery, Ankara Oncology Training and Research Hospital,

Ankara, Turkey

G. Hafiz

Department of Otorhinolaryngology and Head and Neck

Surgery, Istanbul University, Medicine Faculty, Istanbul, Turkey

M. Enoz $(\bowtie)$

Deniz Abdal Mah. Veled Celebi Sok. No. 42 Isık Apt. A-Blok,

Daire :9, 34092 Findikzade, Istanbul, Turkey

e-mail: muratenoz@gmail.com 